Volume 2 (2), April $2020: 1-8$

http://jurnal.polbangtanyoma.ac.id/index.php/jppt

\title{
Analisis Kelayakan Usaha Penggemukan Sapi Potong Molan Kecamatan Binjai Barat Kota Binjai
}

\section{Feasibility Analyses of Molan Cattle Fattenning in West Binjai Regency Binjai City}

\author{
Ruth Dameria Haloho \\ Dosen Agribisnis Universitas Quality Berastagi \\ Sempajaya Kecamatan Berastagi Kabupaten Karo Sumatra Utara \\ Email: ruthdameria28@gmail.com
}

Diterima : 5 Januari 2020

Disetuju : 2 April 2020

\begin{abstract}
ABSTRAK
Penelitian ini bertujuan untuk mengetahui kelayakan Usaha Peternakan khususnya pada aspek finansial yaitu tingkat keuntungan atas investasi, mengetahui NPV dari investasi, mengetahui manfaat dibandingkan dengan biaya dan mengetahui tingkat bunga pada saat investasi kembali pada Usaha Penggemukkan Sapi Potong Molan di Kecamatan Binjai Barat Kota Binjai. Metode penelitian yang digunakan yaitu metode studi kasus. Pemilihan lokasi penelitian dengan pertimbangan usaha Peternakan Sapi Potong Molan merupakan usaha yang menguntungkan karena mampu melakukan budidaya ternak secara mandiri. Metode pengambilan data yaitu metode observasi dan wawancara langsung. Metode analisis data secara deskriptif dan kuantitatif. Hasil penelitian menunjukkan ROI sebesar $40,97 \%$ lebih besar dari pada tingkat bunga deposito Bank BRI sebesar 4,5\%. NPV sebesar Rp 130.174.744,9 bernilai lebih besar dari Nol. Nilai Net BC ratio 1,18 lebih besar dari 1. Nilai IRR sebesar $22,32 \%$ lebih besar dari tingkat bunga kredit bank BRI sebesar 7\%. Kesimpulan dari penelitian ini adalah usaha penggemukkan sapi potong Molan dinyatakan layak secara finansial karena mampu menghasilkan laba atas investasi yang ditanamkan dan penerimaan yang diterima lebih besar daripada pengeluaran sehingga usaha menguntungkan dan layak untuk dikembangkan.
\end{abstract}

Kata Kunci: kelayakan usaha, sapi potong, penggemukkan

\section{ABSTRACK}

This study aims to determine the feasibility of livestock business, especially in the financial aspect, namely the level of return on investment, knowing the NPV of investment, knowing the benefits compared to costs and knowing the interest rate at the time of reinvestment in Molan Beef Cattle Fattening Business in Binjai Barat District, Binjai City. The research method used is the case study method. The choice of research location with the consideration of Molan Beef Cattle Fattening business is a profitable business because it is able to carry out livestock cultivation 
independently. The data collection method is the method of observation and direct interviews. Methods of data analysis are descriptive and quantitative. The results showed that the ROI was $40.97 \%$ greater than the BRI Bank deposit interest rate of $4.5 \%$. NPV of Rp. $130,174,744.9$ is worth more than zero. The Net $B C$ ratio value of 1.18 is greater than 1 . The IRR value of $22.32 \%$ is greater than the BRI bank loan interest rate of $7 \%$. The conclusion of this research is that the business of Molan beef cattle fattening is declared financially feasible because it is able to generate a return on investment and the income received is greater than the expenditure so that the business is profitable and feasible to develop.

Key words: feasibility, beef cattle, fattening.

\section{PENDAHULUAN}

Usaha Peternakan adalah kegiatan usaha budidaya ternak untuk menghasilkan bahan pangan, bahan baku industri, dan kepentingan masyarakat lainnya di suatu tempat tertentu secara terus menerus (kemenkeu.go.id). Usaha peternakan sapi di Indonesia masih menjadi sektor yang perlu dikembangkan, mengingat akan kebutuhan daging yang semakin meningkat, namun belum terpenuhi dari produksi daging dalam negeri. Salah satu usaha mencapai stabilitas ketersediaan daging sapi yaitu melalui peningkatan usaha penggemukan sapi potong yang memiliki prospek jangka Panjang (Lestari et al., 2015).

Kota Binjai merupakan daerah yang berpotensi dalam pengembangan usaha sapi potong. Hal ini terlihat dari jumlah populasi yang terus meningkat dari Tahun 2016 sebanyak 6.365 ekor, Tahun 2017 sebanyak 6.630 dan Tahun 2018 7.527(ditjenpkh.pertanian.go.id). Usaha Penggemukan sapi potong Molan merupakan usaha peternakan yang berada di Kecamatan Binjai Barat Kota Binjai. Usaha ini didukung dengan ketersedian pakan yaitu rumput gajah dan setiap tahunnya mengalami peningkatan populasi sapi potong (Haloho, 2020). Oleh karena itu perlu dilaksanakan analisis usaha apakah usaha tersebut layak untuk diusahakan Analisis usaha kelayakan penggemukkan sapi potong sangat penting untuk dilakukan, agar kedepannya usaha yang dijalankan tidak mengalami kegagalan dan merupakan alat ukur apakah usaha sapi potong memberikan keuntungan yang berjangka panjang bagi peternak. Peternakan sapi potong merupakan peternakan yang paling banyak diusahakan, oleh karena itu diharapkan dapat memberikan kontribusi dalam peningkatan kesejahteraan peternak.

Tujuan dari penelitian ini adalah untuk mengetahui kelayakan Usaha Peternakan khususnya pada aspek finansial. Manfaat dari penelitian ini diharapkan akan memberikan gambaran apakah usaha Peternakan sapi potong Molan di Kecamatan Binjai Barat Kota Binjai dapat dinyatakan layak secara finansial atau tidak, sehingga rekomendasi tersebut dapat digunakan untuk dasar pengembangan usaha peternakan sapi potong pada masa yang akan datang.

\section{MATERI DAN METODE}

Usaha Peternakan dilaksanakan di berlokasi di Kelurahan Sukamaju Kecamatan Binjai Barat Kota Binjai. Penelitian dilaksanakan pada Bulan November- Desember 2019. Pelaksanaan Penelitian menggunakan metode studi kasus. Data yang 
digunakan dalam penelitian ini diperoleh dari data primer dan sekunder. Data primer diperoleh dari hasil wawancara dengan survei langsung ke lapangan dan hasil wawancara kepada pemilik dan karyawan usaha peternakan Molan dengan menggunakan bantuan kuesioner mengenai aspek teknis dan keuangan. Data sekunder merupakan data pelengkap yang diperoleh dari instansi/lembaga, buku, ataupun literatur yang berhubungan dengan penelitian yang dilakukan.

Analisis data dilakukan dengan metode deskriftif dan kuantitatif. Metode analisis kelayakan usaha dengan aspek finansial dianalisis melalui ROI, NPV, $B C R$, dan IRR. Data tersebut ditabulasi dan dihitung serta dianalisis menggunakan kriteria (Soekardono, 2009). Cara perhitungan analisis finansial yaitu

1. $\mathrm{ROI}=\frac{\text { laba setelah pajak }}{\text { total investasi }} \times 100 \% \ldots$... 1 (1)

2. NPV

$$
\mathrm{NPV}=\sum_{t=1}^{n} \frac{B t-C_{t}}{(1+i)^{t}}
$$

\section{Keterangan}

a) $B_{t}=$ merupakan benefit sosial kotor sehubungan dengan sesuatu proyek pada tahun $\mathrm{t}$

b) $\mathrm{C}_{\mathrm{t}}=$ merupakan biaya sosial kotor sehubungan dengan proyek pada tahun $\mathrm{t}$

c) $\mathrm{i}=$ Discount factor

d) $n=$ umur ekonomis dari pada proyek

e) $\mathrm{t}=$ tahun, tahun pertama adalah sebagai tahun pertama investasi atau tahun ke 0

\section{Kaidah Keputusan :}

NPV $>0$ (NPV positif) : maka usaha tersebut layak dilaksanakan, karena benefit yang diterima lebih besar daripada biaya yang dikeluarkan.

$\mathrm{NPV}<0$ (NPV negatif): maka usaha tersebut tidak layak untuk dilaksanakan, karena biaya yang dikeluarkan lebih besar daripada benefit yang diterima

\section{BCR}

Net BCR =

$\sum$ Present Value Net Benefit yang positip

$\sum$ Present Value Net Benefit yang negatip

\section{Kaidah keputusan}

Net BCR $>1$ : maka usaha tersebut menguntungkan dan layak beroperasi.

Net BCR $<1$ : maka usaha tersebut tidak menguntungkan dan tidak layak beroperasi.

4.IRR $=i_{1}+\left\{\frac{\mathrm{NPV}_{1}}{\mathrm{NPV}_{1}-\mathrm{NPV}_{2}}\right\}\left(\mathrm{i}_{2}-\mathrm{i}_{1}\right) .$.

Keterangan :

i1 = tingkat bunga percobaan 1

NPV1 = NPV saat tingkat bunga percobaan 1

i2 = tingkat bunga percobaan 2

NPV2 = NPV saat tingkat bunga percobaan 2

\section{Kaidah keputusan:}

IRR>tingkat bunga kredit bank, berarti tingkat bunga laba usaha lebih besar sehingga usaha tersebut layak beroperasi.

IRR<tingkat bunga kredit bank berarti tingkat bunga laba usaha lebih rendah, sehingga usaha tersebut tidak layak beroperasi.

\section{HASIL DAN PEMBAHASAN}

\section{Pembahasan Investasi}

Biaya Investasi adalah biaya yang dikeluarkan oleh pemilik saat memulai usaha penggemukan sapi potong. Biaya investasi meliputi pembuatan kandang sebesar Rp 400.000.000, lahan Sebesar Rp 150.000.000, kendaraan sebesar $R p$ 100.000.000, Instalasi listrik sebesar Rp 10.000.000, Instalasi air sebesar Rp 15.000.000 dan Mesin Chopper sebesar Rp 40.000.000 (Tabel 1). Biaya investasi terbesar adalah biaya Pembuatan kandang. Hal ini sesuai dengan penelitian Sahala et al (2016) yang menyatakan bahwa investasi 
terbesar dalam usaha penggemukkan sapi potong adalah pembuatan kandang.

Tabel 1. Investasi Usaha Penggemukkan Sapi Potong Molan

\begin{tabular}{llr}
\hline No & Keterangan & Jumlah (Rp) \\
\hline 1 & Kandang & 400.000 .000 \\
2 & Lahan & 150.000 .000 \\
3 & Kendaraan & 100.000 .000 \\
4 & Instalasi listrik & 10.000 .000 \\
5 & Instalasi air & 15.000 .000 \\
6 & Mesin Chopper & 40.000 .000 \\
\hline & Jumlah & 715.000 .000 \\
\hline
\end{tabular}

Sumber : Data Primer diolah (2019)

\section{Penerimaan}

Penerimaan adalah segala sesuatu yang dapat meningkatkan pendapatan sebuah proyek (Sunarto et al., 2016). Penerimaan pada usaha penggemukkan sapi potong molan berasal dari penjualan sapi. Sapi yang dijual adalah sapi yang digemukkan selama 6 bulan per periode penggemukkan dijual dengan bobot hidup.

Tabel 2. Penerimaan Usaha Penggemukkan Sapi Potong Molan Tahun 2017-2019

\begin{tabular}{clccc}
\hline Tahun & Uraian & Unit (ekor) & Harga (Rp) & Jumlah (Rp) \\
\hline 2017 & Penjualan Sapi Potong & 50 & 12.500 .000 & 625.000 .000 \\
2018 & Penjualan Sapi Potong & 100 & 13.000 .000 & 1.350 .000 .000 \\
2019 & Penjualan Sapi potong & 150 & 13.000 .000 & 1.950 .000 .000 \\
\hline
\end{tabular}

Sumber : Data Primer diolah (2019)

Berdasarkan hasil penelitian Tabel 2 setiap tahun terjadi peningkatan penerimaan hasil penjualan sapi potong yaitu Tahun 2017 sebesar Rp 625.000.000, Tahun 2018 sebesar Rp 1.350.000.000 dan Tahun 2019 sebesar Rp 1.950.000.000. Peningkatan penerimaan dikarenakan oleh jumlah ternak yang dipelihara setiap tahunnya bertambah Tahun 2017 dipelihara sebanyak 50 ekor, Tahun 2018 dipelihara 100 ekor dan Tahun 2019 dipelihara sebanyak 150 ekor. Penerimaan yang diperoleh berasal dari jumlah ternak yang jual dikali dengan harga jual ternak. Berdasarkan hasil penelitian Halid et al (2017) yang menyatakan bahwa penerimaan adalah hasil dari perkalian jumlah produksi saat penjualan dengan harga jual,

\section{Biaya Produksi}

Besaran biaya yang dikeluarkan dalam proses produksi akan menjadi acuan dalam penentuan harga pokok penjualan dan akan mempengaruhi kelayakan usaha. Biaya yang dikeluarkan dalam usaha penggemukkan sapi potong Molan adalah biaya tetap dan biaya tidak tetap. Biaya tetap yang dikeluarkan terdiri dari penyusutan kendang, penyusutan pemotong rumput, penyusutan instalasi listrik, penyusutan instalasi air, penyusutan kendaraan, tenaga kerja dan listrik. Biaya tidak tetap terdiri dari rumput, konsentrat, obat-obatan. Biaya produksi yang terbesar adalah biaya pembelian sapi bakalan Tahun 2017 sebesar Rp 325.000.000, Tahun 2018 sebesar Rp 680.000.000 dan Tahun 2019 sebesar Rp 1.050.000.000 ( Tabel 3). Hal ini sesuai dengan penelitian Budirahardjo et al (2011) yang menyatakan bahwa biaya terbesar dalam usaha penggemukan sapi potong adalah pembelian bakalan sapi. 
Tabel 3. Biaya Produksi Usaha Penggemukkan Sapi Potong Molan Tahun 20172019

\begin{tabular}{|c|c|c|c|c|}
\hline No & Rincian & $\begin{array}{l}\text { Tahun } 2017 \\
\text { Jumlah (Rp) }\end{array}$ & $\begin{array}{l}\text { Tahun } 2018 \\
\text { Jumlah (Rp) }\end{array}$ & $\begin{array}{l}\text { Tahun } 2019 \\
\text { Jumlah (Rp) }\end{array}$ \\
\hline & Biaya Tetap & & & \\
\hline 1. & Penyusutan kandang & 12.000 .000 & 12.000 .000 & 12.000 .000 \\
\hline 2 & $\begin{array}{l}\text { Penyusutan pemotong } \\
\text { rumput }\end{array}$ & 3.600 .000 & 3.600 .000 & 3.600 .000 \\
\hline 3 & Penyusutan Instalasi listrik & 600.000 & 600.000 & 600.000 \\
\hline 4 & Penyusutan Instalasi air & 900.000 & 900.000 & 900.000 \\
\hline 5 & Penyusutan Kendaraan & 9.000 .000 & 9.000 .000 & 9.000 .000 \\
\hline 6 & Tenaga Kerja & 15.0000 .000 & 22.000 .000 & 36.000 .000 \\
\hline 7 & Listrik & 500.000 & 800.000 & 1.200 .000 \\
\hline \multirow[t]{3}{*}{8} & PBB & 700.000 & 800.000 & 900.000 \\
\hline & Jumlah & 46.800 .000 & 56.900 .000 & 75.000 .000 \\
\hline & Biaya Tidak tetap & & & \\
\hline 1 & Rumput & 21.000 .000 & 50.000 .000 & 81.000 .000 \\
\hline 2 & Konsenterat & 63.000 .000 & 162.000 & 270.000 .000 \\
\hline 3 & Obat-obatan & 200.000 & 400.000 & 600.000 \\
\hline 4 & Transport & 3.500 .000 & 5.000 .000 & 8.000 .000 \\
\hline \multirow[t]{3}{*}{5} & Sapi Bakalan & 325.000 .000 & 680.000 .000 & 1.050 .000 .000 \\
\hline & Jumlah & 412.700 .000 & 897.400 .000 & 1.409 .600 .000 \\
\hline & Biaya Produksi & 459.500 .000 & 954.300 .000 & 1.484 .600 .000 \\
\hline
\end{tabular}

Sumber : Data Primer Diolah (2019).

\section{Pendapatan}

Pendapatan penggemukkan Sapi Potong Molan diperoleh dari total penerimaan dikurangi total biaya produksi. Pendapatan tersebut merupakan laba sebelum pajak yang apabila dikurangi pajak pendapatan menghasilkan laba bersih setelah pajak. Besar kecilnya pendapatan tergantung dari penerimaan yang berasal dari harga jual ternak dikali jumlah ternak yang dipelihara dan biaya yang dikeluarkan dalam proses produksi. Berdasarkan Tabel 4 besarnya pendapatan yang diperoleh dapat dilihat dari jumlah penerimaan , biaya produksi dan pajak. Berdasarkan hasil penelitian Mlote et al (2013) yang menyatakan bahwa keuntungan usaha penggemukkan sapi potong diperoleh dari jumlah penerimaan, biaya total dan tenaga kerja. Jumlah keuntungan diperoleh dari harga akhir ternak sementara biaya total dari harga awal ternak.

Tabel 4. Pendapatan Usaha Penggemukkan Sapi Potong Molan

\begin{tabular}{lrrr}
\hline Rincian & $\begin{array}{c}\text { Tahun 2017 } \\
\text { Jumlah (Rp) }\end{array}$ & $\begin{array}{c}\text { Tahun 2018 } \\
\text { Jumlah (Rp) }\end{array}$ & \multicolumn{1}{c}{$\begin{array}{l}\text { Tahun 2019 } \\
\text { Jumlah (Rp) }\end{array}$} \\
\hline Total Penerimaan & 625.000 .000 & 1.350 .000 .000 & 1.950 .000 .000 \\
Total Biaya & 459.500 .000 & 954.300 .000 & 1.484 .600 .000 \\
Produksi & & & \\
Pendapatan/Laba & 165.500 .000 & 345.700 .000 & 465.400 .000 \\
Pajak & 16.550 .000 & 34.570 .000 & 46.540 .000
\end{tabular}


Laba

Setelah pajak

Sumber : Data Primer Diolah (2019).

\section{Analisis Kelayakan Usaha}

Faktor finansial menjadi tolok ukur utama dari suatu analisis usaha, terutama cash flow yang terjadi selama kegiatan usaha berjalan. Perhitungan besarnya biaya, keuntungan yang diperoleh dan harga jual pokok penjualan dilakukan untuk mengetahui indikator kelayakan suatu usaha. metode yang digunakan untuk mengukur kelayakan finansial adalah metode penilaian investasi yang meliputi analisis ROI, NPV, BCR dan IRR. Hal ini sesuai dengan penelitian Makkan et al (2014) yang menyatakan bahwa indicator untuk menghitung suatu kelayakan usaha adalah NPV, BCR dan IRR.

Tabel 5. Analisis Kelayakan Usaha Penggemukkan Sapi Potong Molan

\begin{tabular}{lll}
\hline No & $\begin{array}{l}\text { Kriteria } \\
\text { Kelayakan }\end{array}$ & Hasil \\
\hline 1 & ROI & $40,97 \%$ \\
2 & NPV & Rp 130.174.744,9 \\
3 & BCR & 1,18 \\
4 & IRR & $22,32 \%$ \\
\hline \multicolumn{3}{l}{ Sumber : Data Primer Diolah (2019). }
\end{tabular}

ROI dihitung dengan membandingkan keuntungan bersih rata-rata dengan investasi yang ditanamkan. Berdasarkan hasil penelitian Tabel 5 diperoleh Nilai ROI yang diperoleh sebesar $40,97 \%$. Hal ini menunjukkan bahwa nilai $\mathrm{ROI}$ hasil perhitungan lebih besar daripada tingkat bunga deposito Bank BRI sebesar 5\% Tahun 2019, artinya peternakan usaha penggemukkan sapi potong Molan mampu menghasilkan keuntungan dari investasi yang ditanamkan dan layak untuk terus dijalankan. Berdasarkan hasil penelitian Umar (2014) menyatakan bahwa usaha penggemukkan sapi potong merupakan usaha yang menguntungkan.

NPV yang diperoleh sebesar Rp 130.174.744,9 yang berarti bahwa keuntungan yang diperoleh lebih besar daripada biaya produksi ditambah investasi. NPV positif berarti proyek tersebut menghasilkan lebih banyak kas dari yang dibutuhkan untuk menutup utang dan memberikan pengembalian yang diperlukan kepada pemodal. NPV lebih besar dari 0 maka usaha dikatakan layak. Hal ini sesuai dengan penelitian Parlindungan et al (2017) menyatakan bahwa analisis kelayakan sapi potong NPV > O maka usaha dikatakan layak.

BCR yang diperoleh sebesar 1,18 menunjukkan bahwa setiap tambahan biaya yang dikeluarkan sebesar $\mathrm{Rp} 1$ akan menghasilkan tambahan manfaat bersih bagi usaha penggemukkan Molan sebesar Rp 1,18. Nilai BCR $>1$ menunjukkan usaha layak untuk dijalankan. Hasil penelitian Lestari et al (2015) yang menyatakan bahwa usaha penggemukkan sapi potong layak diusahakan karena peternak mendapatkan keuntungan dari usaha tersebut.

IRR yang diperoleh sebesar $22,32 \%$ Nilai IRR tersebut berarti bahwa pada tingkat bunga tersebut $(22,32 \%)$ nilai NPV sama dengan 0 . Nilai IRR yang lebih besar dari tingkat bunga kredit bank $\mathrm{BRI}$ sebesar $7 \%$ sehingga usaha penggemukan sapi potong di Kecamatan Binjai layak untuk diusahakan. Hasil penelitaian Steflyando (2014) yang menyatakan bahwa usaha penggemukan sapi potong dengan IRR sebesar 12,3\% lebih besar dari bunga kredit Bank layak dijalankan. 


\section{KESIMPULAN}

Usaha Penggemukkan Sapi Potong Molan layak untuk dijalankan dengan hasil perhitungan ROI sebesar 40,97\% lebih besar dari pada tingkat bunga depositi Bank BRI sebesar 4,5\%. NPV sebesar Rp 130.174.744,9 bernilai lebih besar dari Nol. Nilai Net BC ratio 1,18 lebih besar dari 1. Nilai IRR sebesar $22,32 \%$ lebih besar dari tingkat bunga kredit bank BRI sebesar $7 \%$.

\section{DAFTAR PUSTAKA}

Budiraharjo, K., M.Handayani dan G. Sanyoto. 2011. Analisis Profitabilitas Usaha Penggemukan Sapi Potong Di Kecamatan Gunungpati Kota Semarang. Mediagro. 7 (1): 1-9.

Halid, A., M. Muhtar., dan S.Y. Mokodompit. 2017. Financial feasibility analysis, small business farm beef cattle livestock in Gorontalo District. Jurnal Perspektif Pembiayaan dan Pembangunan Daerah Vol. 5(2): 105-114

Haloho, R. D. 2020. Analisis Usaha Penggemukan Sapi Potong Dengan Menggunakan Paradigma Agribisnis (Studi Kasus Pada Peternakan Sapi Potong Molan) di Kecamatan Binjai Barat Kota Binjai Provinsi Sumatera Utara. Agrimor 5 (1) : 17-19.

Lestari, R. D., L. M. Baga., R. Nurmalina. 2015. ANALISIS KEUNTUNGAN FINANSIAL USAHA PENGGEMUKAN SAPI POTONG DI KABUPATEN BOJONEGORO. SEPA 11 (2): $207-215$.

Makkan, Annie, Elly, dan Lumenta. 2014. Analisis Keuntungan Penggemukan Sapi Potong Kelompok Tani "Keong Mas"
Desa Tambulango Kecamatan Sangkub Bolaang Mongondow Utara (studi Kasus). Jurnal Zootek Vol 34 No.1 28- 36.

Mlote, S.N., Mdoe N.S.Y., Isinika A.C and L.A. Mtenga. 2013. Profitability analysis of small scale beef cattle fattening in the Lake Zone, Tanzania. J. Agric. Econ. Dev. 2 (5): 203-216.

Parlindungan, MD., A.Yusdiarta dan $\mathrm{H}$. Miftah. 2017. Analisis Kelayakan Finansial Peningkatan Kapasitas Produksi Sapi Potong. 2017. Jurnal Pertanian 8 (2) : 113-120.

PERATURAN

PEMERINTAH REPUBLIK INDONESIA NOMOR 6 TAHUN 2013 TENTANG PEMBERDAYAAN PETERNAK. 2013.

https://jdih.kemenkeu.go.id/fullTe xt/2013/6TAHUN2013PP.HTM.

Diakses 1 Maret 2020.

Sahala, J. R. Widiati dan E. Baliarti. 2016. Analisis Kelayakan Finansial Usaha Penggemukan Sapi Simmental Peranakan Ongole Dan Faktor-Faktor Yang Berpengaruh Terhadap Jumlah Kepemilikan Pada Peternakan Rakyat Di Kabupaten Karanganyar. Buletin Peternakan .40 (1): 75-82

Soekardono. 2009. Ekonomi Agribisnis Peternakan Teori dan Aplikasinya, Akademika Pressindo, Jakarta.

Sunarto, E., O. H. Nono., U. R. Lolea, dan H.Y. Sikone. 2016. Analisis Finansial Sistim Penggemukan Sapi Potong oleh Perusahaan dan Peternakan Rakyat di Kabupaten Kupang. Journal of Animal Science. 1 (4) : 46-4.

Statistik peternakan dan kesehatan hewan. 2019. Kementerian Pertanian Direktorat Jenderal Peternakan dan Kesehatan Hewan. 
http://ditjenpkh.pertanian.go.id. Di akses 07 Desember 2019

Steflyando, R., Abubakar dan A. Sale. 2014. Analisis Kelayakan Usaha Sapi Potong Dengan Metode Zero Waste Farming Di Kecamatan Parongpong. JuRNAL Teknik Industri Itenas.4 (1): 226-237.

Umar, A. S.S. 2014. Financial Analysis of Small Scale Cattle Fattening Enterprise in Bama Local Government Area of Borno State, Nigeria. Journal of Resources Development and Management. 3: 